\title{
Integrating Fire, Structure and Agent Models*
}

\author{
A.R. Chaturvedi ${ }^{1}$, S.A. Filatyev ${ }^{2}$, J.P. Gore ${ }^{2}$, A. Hanna ${ }^{1}$, \\ J. Means ${ }^{1}$, and A.K. Mellema ${ }^{1}$ \\ ${ }^{1}$ Purdue Homeland Security Institute, Purdue University, West Lafayette, IN 47907 \\ ${ }^{2}$ School of Mechanical Engineering, Purdue University, West Lafayette, IN 47907
}

\begin{abstract}
A state-of-the-art integrated environment was created to study interaction among fire, structure and agent models in a fire evacuation from a typical office building. For the fire simulations NIST large-eddy simulation code Fire Dynamics Simulator (FDS) was used. The code is based on a mixture fraction model. FDS provided time resolved temperature, $\mathrm{CO}, \mathrm{CO} 2$, soot distribution in the building. The agent software was designed to simulate agent behaviors during evacuation by tracking the behavior of each individual in the building taking into account effects of temperature, $\mathrm{CO}$, and soot on the behavior and health for each agent. The created integrated environment was designed to provide the bridge between multiple simulations for data transfer and model interaction. It was shown that fire position, agent positions, and number of exits available affect significantly agents' health and death toll. The results can be used for better fire safety building design and regulations.
\end{abstract}

\section{Introduction}

As the complexity of buildings increases, it becomes more and more challenging to provide a satisfactory level of fire safety in the buildings. Even if the building satisfies modern fire safety codes, it does not necessarily guarantee needed safety levels to the occupants.

The events of September 11, 2001 showed necessity of better response training in case of emergencies such as terrorist attack on a big building. In order to prepare for such an event, an understanding of the event is required. Such understanding can come from scientific analysis of human/environmental interaction. In case of explosion or arson in a building, such as that studied in the present paper, the important aspects are fire propagation, human interaction with the fire, interaction between the fire and the building structure. Realistic models describing fire, structure response, and human behavior are needed for such simulations, as well as an environment where those models run simultaneously and interact with each other during execution. Currently, models exist which simulate fire, human behavior during evacuation and building structure, but these models have yet to be integrated to simulate real-time events and decisions [1].

" This research is partially funded by NSF ITR grant \# CNS-0325846. 


\section{Goal}

The goal of the project is to create a state-of-the-art integrated environment to study interaction between fire, structure and agents in emergencies situations. Realistic and complex models of fire, structure, and agent were used in order to simulate realistic behavior. These three simulations are normally run independently which created the need for a medium to transfer information from one simulation to another. In order to do this the shared reality environment was created.

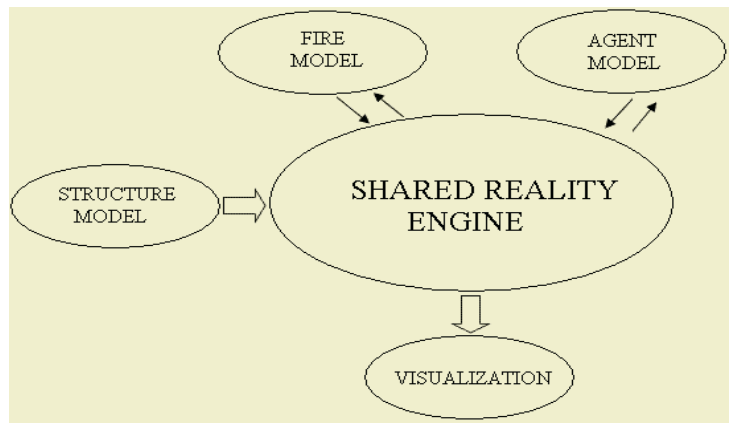

Fig. 1. Shared reality concept

\section{Data Format}

The original building layout was produced in 3D Studio Max. The format needed to be changed for the needs of fire, structure, and agent models since each program was developed independently and uses different input formats. The conversion was done in the shared reality engine [1,2]. At each second of the scenario all three models calculated changes and decisions based on input describing events that took place during the previous second. The output of one model was obtained by the shared reality engine, converted to the formats for the other models and transferred to them. All outputs were then collected by the shared reality engine and converted to text format which was read by the $3 \mathrm{D}$ visualization used for analysis. The visualization allowed for the presentation of the impact of certain emergencies, to find the correct measured response and, if possible, to adjust modifications to building plans.

\section{Models}

The original scenario was evacuation from an office building floor in case of fire with realistic fire model simulations and agent simulation capturing individual agent behavior. 


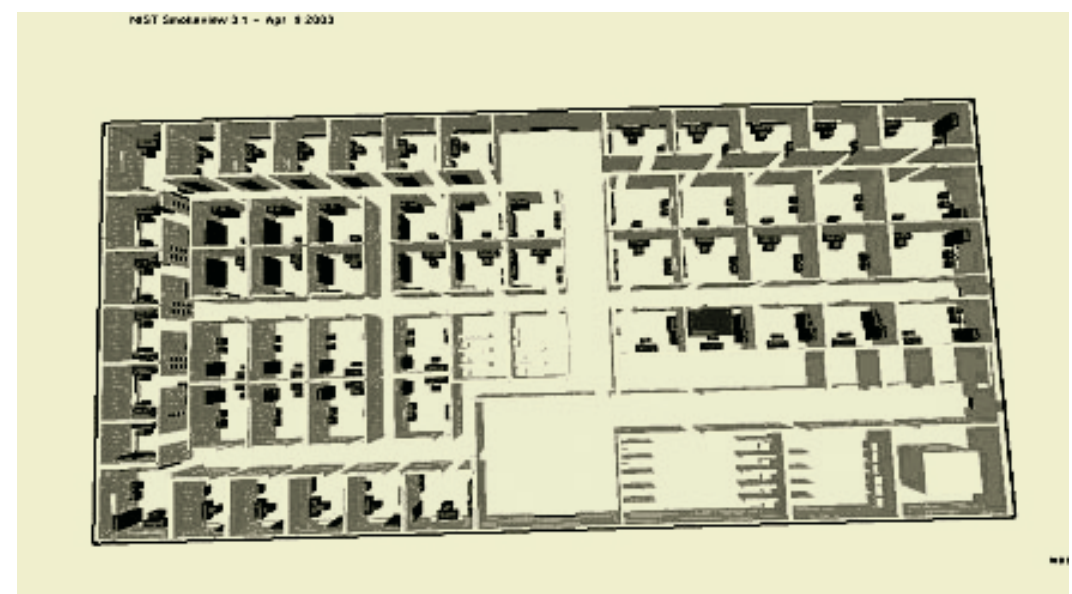

Fig. 2. Plan of the floor used in both fire and agent simulations

\subsection{Geometry}

The geometry used in calculations represented a typical floor of an office building. Physical dimensions were $50 \mathrm{~m}$ by $30 \mathrm{~m}$ by $3 \mathrm{~m}$; the building layout is shown in Figure 2. The building had windows and doors open to the environment during simulations at all times. Office doors were also open at all times. Almost every office along the perimeter had an open window. There were five exits, three along the West wall (left), one main exit on the South wall (bottom), and one exit on the North wall (top). Changes in the structure of the building were calculated using LS-DYNA $[3,4]$.

\subsection{Fire Model}

Fire was simulated using the Fire Dynamics Simulator (FDS 4) program developed by NIST [5]. FDS 4 is a large-eddy simulation (LES) turbulent code which employs the mixture fraction model. The code has been successfully used to describe different processes from fundamental combustion studies of plumes [6] to the replication of 2001 fire of the World Trade Center [7].

For the current simulations all walls, the ceiling and the floor were assumed to have flammable properties. It was assumed that the fire started as a result of arson. To accomplish this numerically a tank of kerosene was placed in one of the rooms and ignited. The tank is shown as a gray rectangle in one of the rooms on the right side of Figure 2. This room has exits into a corridor separating the floor into almost equal parts (top and bottom) in Figure 2.

For calculations, a parallel version of FDS 4 was used. The calculations were done on an IBM SP2 computer using four processors. The total grid size was $360 \times 250 \times 20$. This required about $10 \mathrm{~GB}$ of memory. The final computations were conducted for 360 seconds which took about 80 CPU hours. 


\subsection{Agent Model}

Initially 48 agents were positioned in different rooms on the floor. Agents started moving towards the exits at the time fire started. Their path was described by a twodimensional $\mathrm{A}^{*}$ algorithm which is a well-known shortest path algorithm [8].

All unobstructed space was divided into nodes. The nodes were placed $14 \mathrm{~cm}$ apart. As agents move from one node to another, they select movements along the path to the nearest exit. Each evacuation path is then recalculated every second. The evacuation path could potentially change due to changes in fire conditions obtained from FDS 4 calculations. A certain value, or cost was assign to every node which represented the cost $(\mathrm{F})$ of a move from one node to another. It was defined as

$$
F=G+H+K,
$$

$G$ was a geometrical factor. If a move from one node to another node was horizontal or vertical, $G$ was increased by 10 . If it was diagonal, $G$ was increased by 14 . In addition the cost of a move was increased if the second node was on fire. That was determined by factor $H$. Factor $H$ included effects of temperature, heat release, and smoke:

$$
\mathrm{H}=\beta_{1} \mathrm{~T}+\beta_{2} \mathrm{HRR}+\beta_{3} \text { Soot },
$$

where $T, H R R$, and Soot are maximum temperature $\left({ }^{\circ} \mathrm{C}\right)$, maximum heat release per unit volume $\left(\mathrm{kW} / \mathrm{m}^{3}\right)$, and maximum soot density $\left(\mathrm{mg} / \mathrm{m}^{3}\right)$ in vertical direction at the current agent position (Xagent, Yagent). $\beta_{1}, \beta_{2}, \beta_{3}$ are constants. Heat release information was used as a flame marker and visible position of the fire. The factor $K$ estimated the distance between the position of an agent and the exit.

$$
K=\mid \text { Xagent }- \text { Xexit }|+| \text { Yagent }- \text { Yexit } \mid,
$$

where Xagent and Yagent are current $\mathrm{x}$ and $\mathrm{y}$ positions of the agent, Xexit and Yexit are $\mathrm{x}$ and $\mathrm{y}$ positions of the exit. From every position an agent could choose up to 8 possible directions to travel. The agent was limited by walls which considered impenetrable. The agents had collision-with-other-agents detection system as well. It prevented two or more agents to occupy the same node. A position one agent occupied at certain time was considered impenetrable by other agents at the same time. The agent moved to the lowest cost $(\mathrm{F})$ position.

It can be seen from (1) - (3) that although an agent cannot walk through the wall it is capable of walking through fire. This consequence is supported by facts that in desperate situations people run through fire. Although it is possible for people to walk through fire it will take a toll on their health.

The agent health will decline while they are evacuating. The formula used in calculations takes into account the temperature, heat release, soot, carbon monoxide, and carbon dioxide. The agents start with health equal to one, decreasing according to the following formula:

$$
\text { Health }_{i}-\text { Health }_{i+1}=\alpha_{1} T+\alpha_{2} H R R+\alpha_{3} \text { Soot }+\alpha_{4} \mathrm{CO}+\alpha_{5} \mathrm{CO} 2,
$$

where $\mathrm{Health}_{i}$ is health of an agent at time $i$ second, $\mathrm{CO}$ is $\mathrm{CO}$ volume fraction (ppm), $\mathrm{CO} 2$ is $\mathrm{CO} 2$ volume fraction (ppm). Soot density, $\mathrm{CO}$ and $\mathrm{CO} 2$ volume fractions are 
maximum values in vertical $(\mathrm{z})$ direction at the agent position as well as temperature and heat release. $\alpha_{1}, \ldots, \alpha_{5}$ are constants. Agents died when their health reached a zero value. The formulas were based on real data for how these elements affect the human body. The CO data is shown in Table 1 [9].

Table 1. Effects of $\mathrm{CO}$ on agents

\begin{tabular}{|c|c|c|c|c|}
\hline \multicolumn{3}{|c|}{$\mathrm{CO}$ in the Atmosphere } & \multirow{2}{*}{$\begin{array}{c}\% \\
\text { Blood } \\
\text { COHb } \\
\end{array}$} & \multirow[t]{2}{*}{ Physiological Symptoms } \\
\hline Percent & mg/cubic meter & ppm & & \\
\hline 0.007 & 80 & 70 & 10 & Shortness of breath upon exertion \\
\hline 0.01 & 140 & 120 & 20 & $\begin{array}{l}\text { Shortness of breath upon moderate } \\
\text { exertion, possible headache }\end{array}$ \\
\hline 0.02 & 250 & 220 & 30 & $\begin{array}{l}\text { Decided headache, dizziness, dimness } \\
\text { of vision, impaired judgment }\end{array}$ \\
\hline $\begin{array}{l}0.035- \\
0.052\end{array}$ & $400-600$ & $\begin{array}{l}350- \\
520\end{array}$ & $40-50$ & $\begin{array}{l}\text { Headache, confusion, fainting, col- } \\
\text { lapse }\end{array}$ \\
\hline $\begin{array}{l}0.080- \\
0.122\end{array}$ & $900-1400$ & $\begin{array}{l}800- \\
1220\end{array}$ & $60-70$ & $\begin{array}{l}\text { Unconsciousness, convulsions, death } \\
\text { if continued exposure }\end{array}$ \\
\hline 0.195 & 2200 & 1950 & 80 & Swiftly fatal \\
\hline
\end{tabular}

\subsection{Agent-Fire Interaction}

Current calculations were done under the assumption that agents do not affect the fire. They cannot either extinguish or increase intensity of the fire by their actions. On the other hand, the fire propagation affects both agent behavior and health. This assumption allowed us to have independent fire simulation. After finishing the fire simulation, the computed data was used as input for the agent simulations.

\section{Results}

Immediately after the ignition of kerosene and consumption of air in the room the fire moved from the room into the corridor and began propagating in the direction of air source, i.e. open windows and doors. Figure 3 shows temperature distribution at time 200 seconds, at 2.4 meters above the floor. At seen from Figure 3, 200 seconds after the fire started it has reached one of the building exits. The quickly-moving fire blocked some agents from exits.

Figure 4 shows evacuation visualization. The smoke shown represents the fire position. Agents are in the process of evacuating the building.

Agents far from the exits were more probable to die due to $\mathrm{CO}$ poisoning and smoke inhalation as a result of being blocked by the fire from exits. Through multiple runs of the scenario it was observed that disallowing escape through various exits 


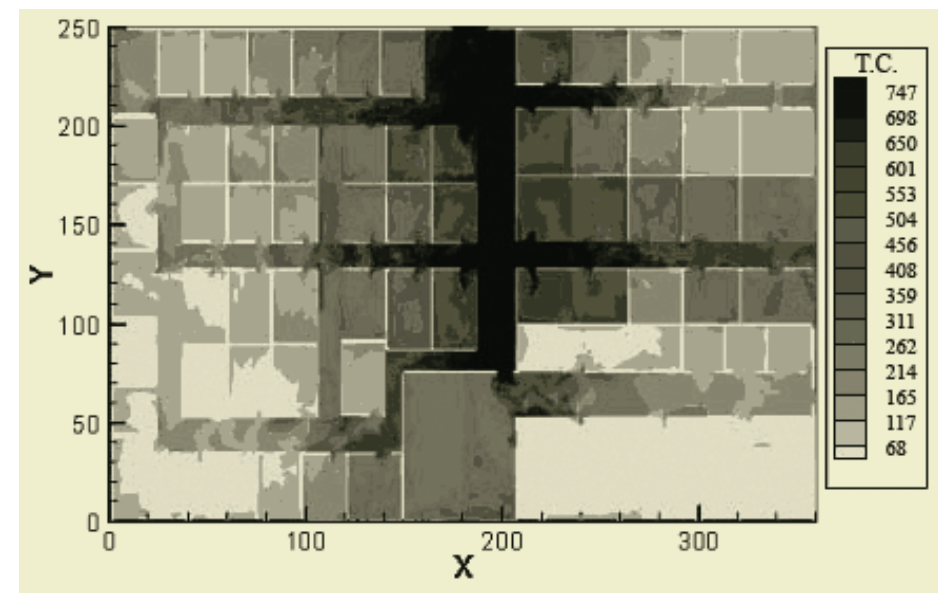

Fig. 3. Temperature distribution at time $200 \mathrm{sec}$. Vertical position is $2.4 \mathrm{~m}$ above the floor

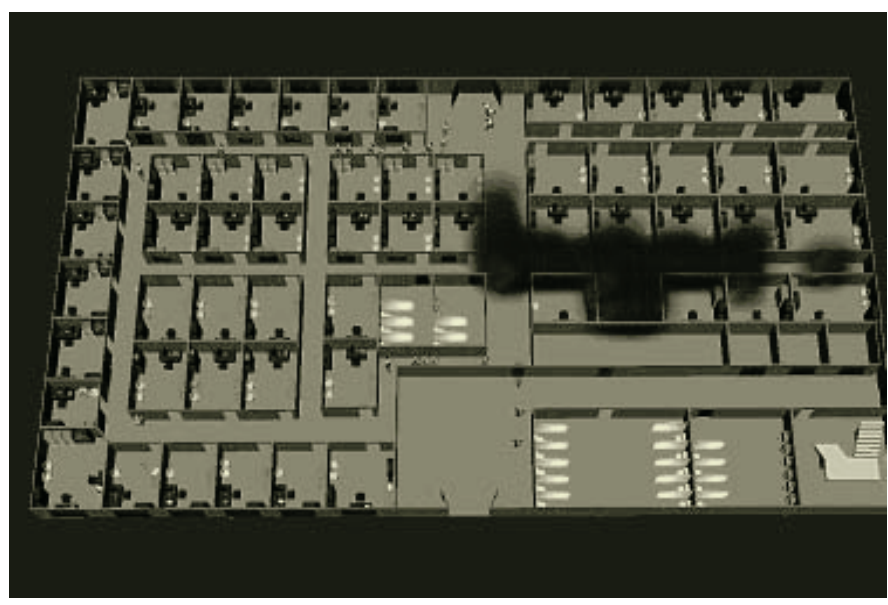

Fig. 4. Visualization of agent evacuation

dramatically affects agent death rate. The death rate with all exits open was 15 out of 48. In replicating the simulation with various combinations of exits closed during evacuation, it can be seen that the two main exits are critical to agent death rate. The death rate with just one of the main exits closed (the exit at the top of Figure 4) was 18 out of 48 , a $6.25 \%$ increase in death rate by closing one exit. Closing both of the main exits (the top and bottom exits of Figure 4) has the most dramatic effect on the death rate: 28 out of 48 agents, a $58.3 \%$ death rate. This is a $20.8 \%$ increase compared to closing only one main exit. Figure 5 shows the evacuation paths of each agent as well as dead agent positions when all exits are open. Figure 6 shows the effect of closing the two main exits. 


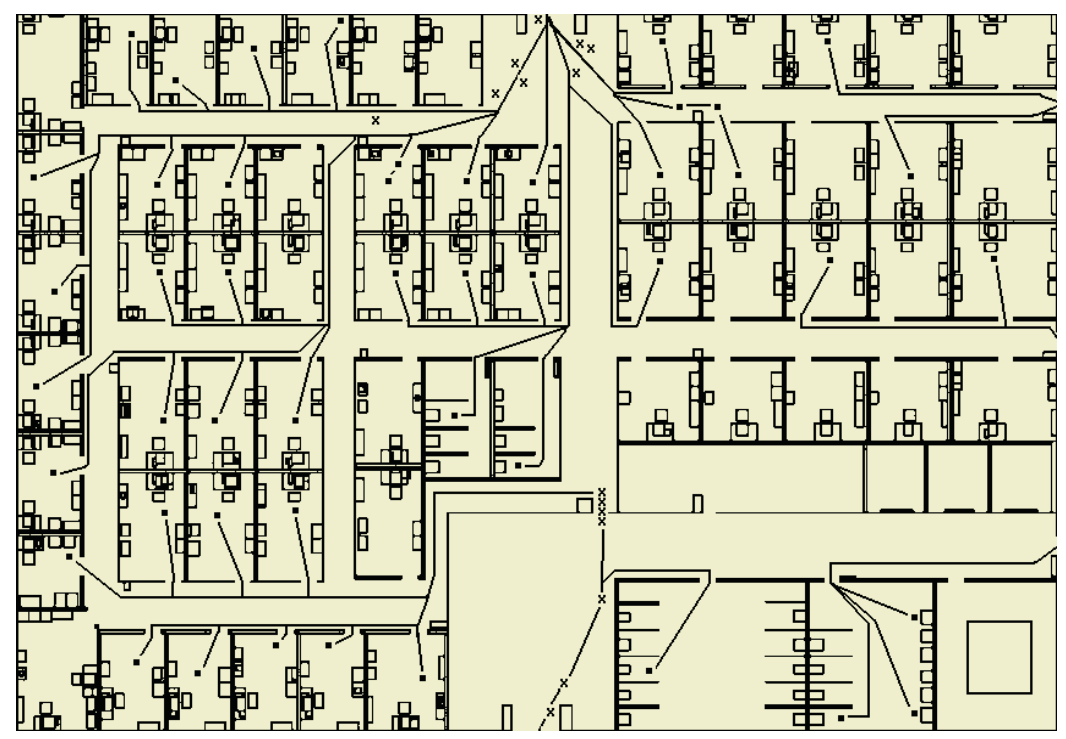

Fig. 5. Agent's evacuation paths with all exits open. Dots represent initial positions, X's represent dead agents

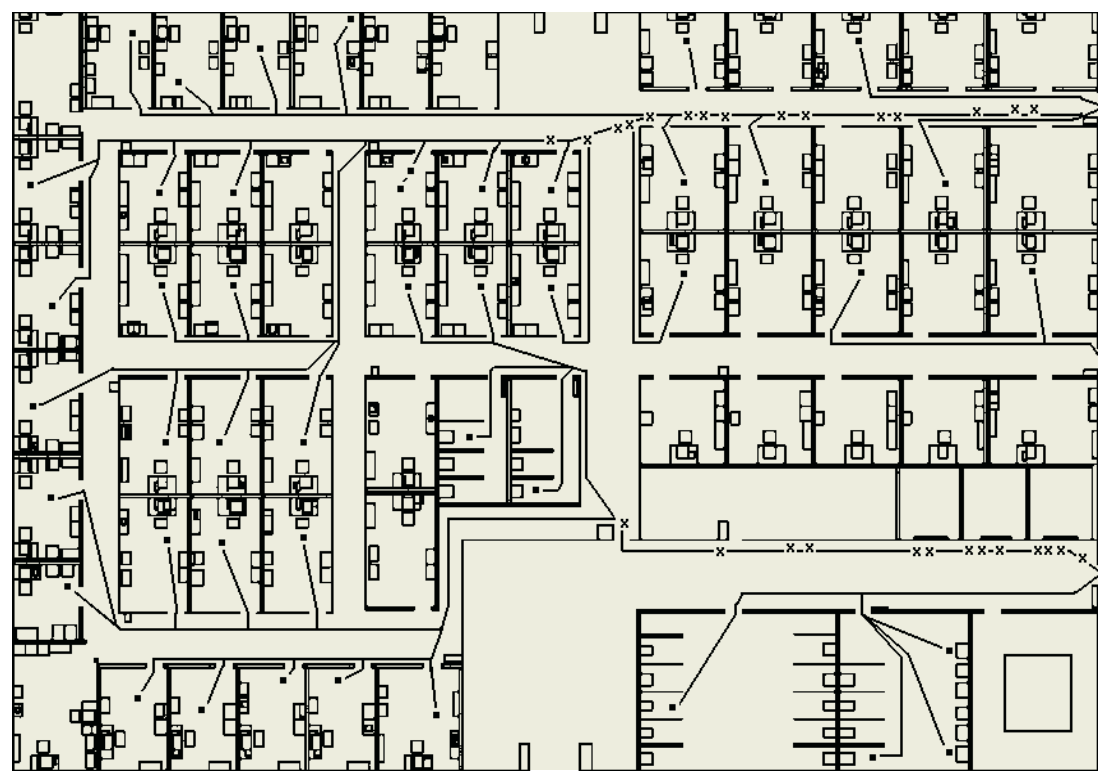

Fig. 6. Agent's evacuation paths with two main exits closed. Dots represent initial positions, $X$ 's represent dead agents 


\section{Conclusions}

The state-of-the-art Shared Reality System was created and successfully tested in case of evacuation of a building on fire. The system included fire simulation (FDS), agent simulation, and the Shared Reality Engine for format conversion. The final results were presented in form of 3D movie visualization. Since fire and agent simulations did not interact directly with each other but through the shared reality, any one simulation can be replaced with a small change in the Shared Reality Engine to accommodate input/output stream from a new code. This change will not affect the remaining code. This provides a significant flexibility in selecting the most convenient and advanced software in each area separately.

\section{References}

1. Foong, C., Armstrong, B., Dilley, D., Grahn, J., Krull, K., Chaturvedi, A., Gore, J., Filatyev, S. "Towards Enabling A Distributed And Scalable Society Of Simulations." 2005 Spring Simulation Multiconference (SpringSim'05) (2005).

2. Chaturvedi, A., Foong, C., Armstrong, B., Dilley, D., Grahn, J., Krull, K., Gore, J., Filatyev, S. "A Society of Simulations." Submitted to Transactions on Systems, Man, and Cybernetics (2005)

3. LS-DYNA. < http://www.ls-dyna.com/>

4. Popescu, V., Hoffmann, C., Kilic, S., Sozen, M., Meador, S. "Producing High-Quality Visualizations of Large-Scale Simulation." Visualization, 2003. VIS 2003. IEEE (2003)

5. McGrattan, K., Forney, G. "Fire Dynamics Simulator (Version 4). Users Guide." NIST Special Publication 1019. 2004 <http://fire.nist.gov/fds>

6. Xin, Y., Gore, J.P., McGrattan, K.B., Rehm, R.G., Baum, H.R. "Fire dynamics simulation of a turbulent buoyant flame using a mixture-fraction-based combustion model." Accepted for publication in Combustion and Flame Journal (2005)

7. Prasad, K., Baum, H. "Coupled Fire Dynamics and Thermal Response of Complex Building Structures." Proceedings of the Combustion Institute 30 (2004).

8. Rabin, S. (2002) AI Game Programming Wisdom. Charles River Media, MA.

9. Canadian Centre for Occupational Health and Safety, International Programme on Chemical Safety. 1999. Carbon Monoxide. <http://www.inchem.org/documents/ ehc/ehc/ehc213.htm> 